\title{
Optimization of Cyclotron Production for Radiometal of Zirconium 89
}

\author{
A.M. Dabkowski ${ }^{a, *}$, S.J. PAisey ${ }^{a}$, M. TAlboys $^{a, b}$ And C. Marshall ${ }^{a}$ \\ ${ }^{a}$ Wales Research and Diagnostic Positron Emission Tomography Imaging Centre (PETIC), School of Medicine, \\ Cardiff University, Heath Park, Cardiff, CF14 4XN, UK \\ ${ }^{b}$ Medical Physics Department, University Hospital of Wales, Heath Park, Cardiff, CF14 4XW, UK \\ Zirconium $89\left({ }^{89} \mathrm{Zr}\right)$ is a promising radionuclide for development of new PET agents due to its convenient half \\ life of $78.4 \mathrm{~h}, \beta^{+}$emission rate of $23 \%$, low maximum energy of $0.9 \mathrm{MeV}$ resulting in good spatial resolution, a \\ stable daughter isotope of yttrium-89 $\left({ }^{89} \mathrm{Y}\right)$ and favorable imaging characteristics, with only one significant $\gamma$-line \\ of $909 \mathrm{keV}$ emitted during decay alongside the $511 \mathrm{keV}$ positron photons. Our aim was to share over 2 years of \\ experience of producing isotopically pure ${ }^{89} \mathrm{Zr}$ via the ${ }^{89} \mathrm{Y}(\mathrm{p}, \mathrm{n}){ }^{89} \mathrm{Zr}$ nuclear reaction with a COSTIS Solid Target \\ System (STS) and CYCLONE 18/9 cyclotron. We optimized the yields without producing either of the long-lived \\ impurities ${ }^{88} \mathrm{Zr}$ or ${ }^{88} \mathrm{Y}$. The degradation of the beam energy with 400 and $500 \mu \mathrm{m}$ thick niobium foils was tested \\ without overheating problems within $2-6 \mathrm{~h}$ of irradiation. From repeated measurements of activity, it was clear \\ that there is a bi-exponential decay of radioactivity due to the short lived ${ }^{89 m} \mathrm{Zr}$ and ${ }^{89} \mathrm{Zr}$. The measured half life \\ of the longer lived radionuclide was consistent with value for ${ }^{89} \mathrm{Zr}$. The energy spectrum from ${ }^{89} \mathrm{Zr}$ had energy \\ peaks at $511 \mathrm{keV}$ and $909 \mathrm{keV}$ and was consistent with ${ }^{89} \mathrm{Zr}$. Production of ${ }^{89} \mathrm{Zr}$ with $400\left(E_{\mathrm{p}}=9.8 \mathrm{MeV}\right)$ and \\ $500 \mu \mathrm{m}\left(E_{\mathrm{p}}=11.6 \mathrm{MeV}\right)$ thick niobium beam degrader was achieved, without producing either ${ }^{88} \mathrm{Zr}$ or ${ }^{88} \mathrm{Y}$. It was \\ necessary to wait at least 4 hours before measuring the activity and decay correct in order to calculate the ${ }^{89} \mathrm{Zr}$ \\ activity at the end of cyclotron production. Degrading the proton beam to $10 \mathrm{MeV}$ produces radionuclidically pure \\ ${ }^{89} \mathrm{Zr}$ with yields from 8 to $9 \mathrm{MBq} / \mu \mathrm{Ah}$. Whilst this is enough for pre-clinical use, the yield is not enough for either \\ clinical use or commercial supply. Use of thinner beam degraders $(400 \mu \mathrm{m})$ increases the proton beam energy and \\ increases the radionuclidic yield to $15.5 \mathrm{MBq} / \mu \mathrm{Ah}$ whilst maintaining radionuclidic purity.
}

DOI: $10.12693 /$ APhysPolA.127.1479

PACS: $87.57 . u \mathrm{k}$

\section{Introduction}

The wide range of biological targeting agents with distribution times of hours and days demands the production of radionuclides with half lives complementary to these biological properties [1] such as the radiometals ${ }^{89} \mathrm{Zr},{ }^{86} \mathrm{Y}$ and ${ }^{64} \mathrm{Cu}$.

${ }^{89} \mathrm{Zr}$ is a promising radionuclide for the development of new immuno-PET agents (in vivo imaging of cancerous tumours and radioimmunotherapy planning) due to the half life of $78.4 \mathrm{~h}$, stable daughter radionuclide ${ }^{89} \mathrm{Y}$, $\beta^{+}$emission rate of $23 \%$ and a low maximum energy $(0.9 \mathrm{MeV})$ of emitted positrons delivering a short range in tissue $(\approx 1 \mathrm{~mm})$ and good spatial resolution as a consequence. ${ }^{89} \mathrm{Zr}$ has one significant $\gamma$-line $(909 \mathrm{keV})$ emitted during decay and giving low contribution to exposure radiation dose for patient and staff.

In PETIC ${ }^{89} \mathrm{Zr}$ is mainly used for antibody labeling. In this application conjugation of the ${ }^{89} \mathrm{Zr}$ to the antibody can be achieved by binding of the apo chelating group desferrioxamne to a lysine side chain of the antibody using a benzyl-NCS linker $\left(37^{\circ} \mathrm{C}, \mathrm{pH} 9,30 \mathrm{~min}\right)$ [2]. The ${ }^{89} \mathrm{Zr}$ is then mixed with the antibody-chelate conjugate at $\mathrm{pH} 7$ and incubated at $37^{\circ} \mathrm{C}$ for $60 \mathrm{~min}$. This preparation can be applied to almost any antibody, allowing rapid testing of new biological targets for PET imaging.

*corresponding author; e-mail: dabkowskia@cardiff.ac.uk
There are three nuclear reactions that have been explored for the production of ${ }^{89} \mathrm{Zr}$ : ${ }^{89} \mathrm{Y}(\mathrm{p}, \mathrm{n}){ }^{89} \mathrm{Zr}$, ${ }^{89} \mathrm{Y}(\mathrm{d}, 2 \mathrm{n}){ }^{89} \mathrm{Zr}$, ${ }^{\text {nat }} \mathrm{Sr}(\alpha, \mathrm{xn}){ }^{89} \mathrm{Zr}$. As PETIC is unable to perform $\alpha$ bombardment, the ${ }^{\text {nat }} \operatorname{Sr}(\alpha, \mathrm{xn}){ }^{89} \mathrm{Zr}$ reaction is not an option. The CYCLONE $18 / 9$ can accelerate deuterons to $9 \mathrm{MeV}$. However, this energy is not sufficiently high for the ${ }^{89} \mathrm{Y}(\mathrm{d}, 2 \mathrm{n}){ }^{89} \mathrm{Zr}$ reaction $[3,4]$.

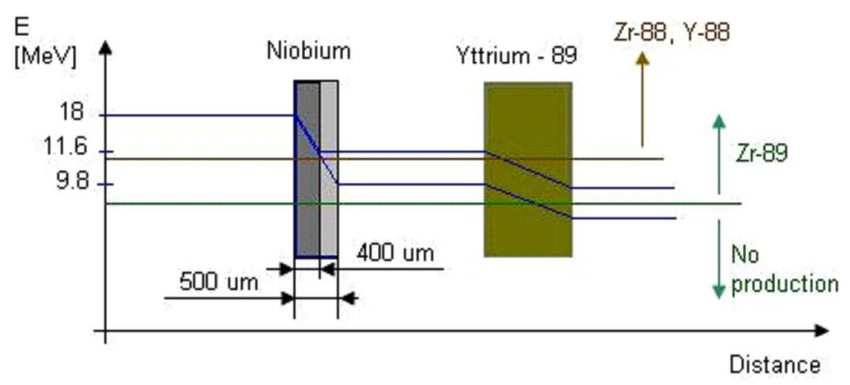

Fig. 1. Schematic picture of the relationship between the Niobium foil thickness and the Zirconium 89 production yield.

Therefore, PETIC decided to investigate the ${ }^{89} \mathrm{Y}(\mathrm{p}, \mathrm{n}){ }^{89} \mathrm{Zr}$ reaction as the product can be made with high radionuclidic purity at low proton energies (10-11 MeV) [5] easily achieved by the CYCLONE 18/9. Long lived radionuclidic impurities may be generated by the competing nuclear reactions ${ }^{89} \mathrm{Y}(\mathrm{p}, 2 \mathrm{n})^{88} \mathrm{Zr}$ (threshold $13.076 \mathrm{MeV}$ ) and ${ }^{89} \mathrm{Y}(\mathrm{p}, \mathrm{pn}){ }^{88} \mathrm{Y}$ (threshold $11.609 \mathrm{MeV})$. Both of these radioisotopes could significantly increase the radiation dose to the patient if 
they were present in the final product. Therefore, both of these production pathways need to be accounted for, and minimised, when producing ${ }^{89} \mathrm{Zr}$. There is a trade off between the purity of the product and efficiency of the ${ }^{89} \mathrm{Zr}$ cyclotron production (Fig. 1).

The proton beam of CYCLONE $18 / 9$ cyclotron had to be degraded from $18 \mathrm{MeV}$ to $10-11 \mathrm{MeV}$ by the niobium window foil installed in the COSTIS STS [6].

Our aim was to prove that usable yields of isotopically pure ${ }^{89} \mathrm{Zr}$ could be produced in an IBA CYCLONE 18/9 cyclotron equipped with a COSTIS STS and a niobium beam degrader without producing either ${ }^{88} \mathrm{Zr}$ or ${ }^{88} \mathrm{Y}$.

\section{Experimental}

\subsection{Solid target design and preparation}

The target material ${ }^{89} \mathrm{Y}$ was obtained as a $150 \mu \mathrm{m}$ thick foil with isotopic purity of $99.9 \%$ from Goodfellow Cambridge Ltd (Fig. 2 - centred).

The solid target holder used in PETIC was based on the design described by Walther et al. [7] (Fig. 3).

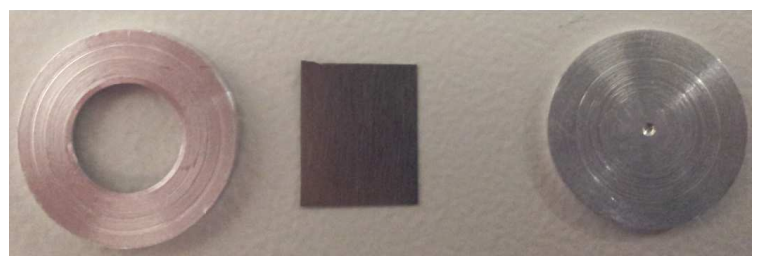

Fig. 2. Aluminum solid target holder with ${ }^{89} \mathrm{Y}$ target foil shown in the center.
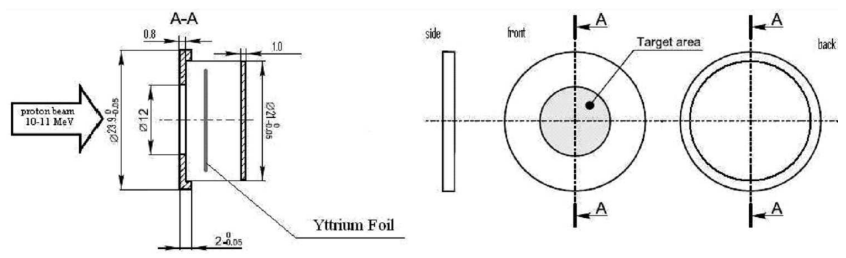

Fig. 3. Solid target "coin" design - aluminum 2-pieces holder and yttrium foil inside.

\subsection{Beam energy degradation}

The proton beam of CYCLONE $18 / 9$ cyclotron was degraded from $18 \mathrm{MeV}$ to $\approx 9.8 \mathrm{MeV}$ using a $500 \mu \mathrm{m}$ thick niobium foil and to $\approx 11.6 \mathrm{MeV}$ using a $400 \mu \mathrm{m}$ thick niobium foil (Fig. 4) (Goodfellow Cambridge Ltd). The energy degradation foil was installed in the COSTIS STS as a vacuum window.

\subsection{Post production measurements}

The COSTIS STS is equipped with a conveyor belt (FlexLink) providing safe transportation of solid targets from the vault (Fig. 5). After irradiation, the coin is released and dropped into an open transport shuttle and waits for a signal from the COSTIS STS to start delivery. Both COSTIS STS and conveyor belt are operated by panels located outside the vault. The automatic closing mechanism was removed from the vault and located on

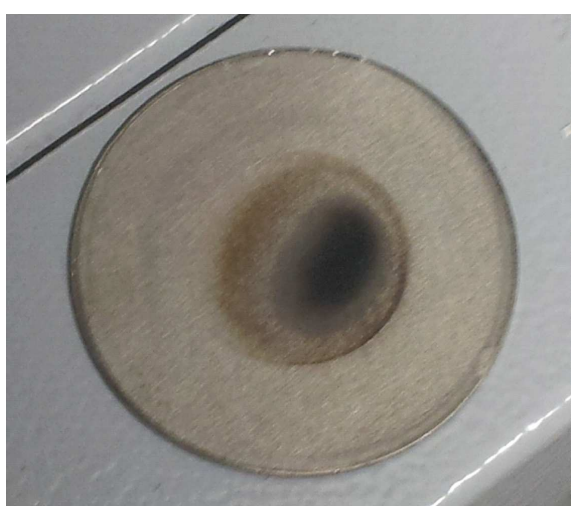

Fig. 4. Used niobium vacuum window for the protons beam energy degradation (note the dark spot - beam trace).

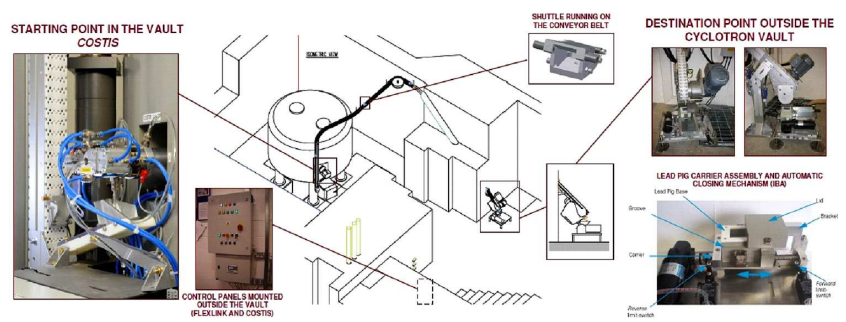

Fig. 5. Schematic view of the solid target disc transportation system.

the other end of conveyor belt. Coins are delivered in lead pigs using the lift from cyclotron suite located one level under the lab. The hot cell has its own loading system (independent of the main hot cell door) with a drawer and hoist for automatic lead pig opening and delivery of radioactive coin. The coin is opened and yttrium foil released for further processing using in house equipment.

The activity of the ${ }^{89} \mathrm{Zr}$ produced was measured using a CRC 25R CAPINTEC Dose Calibrator set to a dial factor of 490 at least $4 \mathrm{~h}$ after the end of beam, to allow for the decay of short lived ${ }^{89 m} \mathrm{Zr}$ which is also produced alongside ${ }^{89} \mathrm{Zr}$, and decay corrected to end of beam (EOB). Capintec CRC-25PET dose calibrators does not have a published calibration factor for ${ }^{89} \mathrm{Zr}$ but a suitable calibration factor was determined through crosscalibration with a CRC-15R dose calibrator (which has a published calibration factor for ${ }^{89} \mathrm{Zr}$ (465) [8]. Long lived impurities were assessed using an EG \& G Ortec (NaI and $\mathrm{HPGe}$ ) detectors with Canberra multi channel analysers.

\section{Results and discussion}

The degradation of the beam energy with 400 and $500 \mu \mathrm{m}$ thick niobium foils were achieved without overheating problems with long irradiation times $(2-6 \mathrm{~h})$.

From repeated measurements of activity (Fig. 6), it is clear that there is a bi-exponential decay of radioactivity due to the short lived ${ }^{89 m} \mathrm{Zr}$ and ${ }^{89} \mathrm{Zr}$. The measured half life of the longer lived radionuclide was $78.841 \mathrm{~h}$ which is consistent with ${ }^{89} \mathrm{Zr}$. 


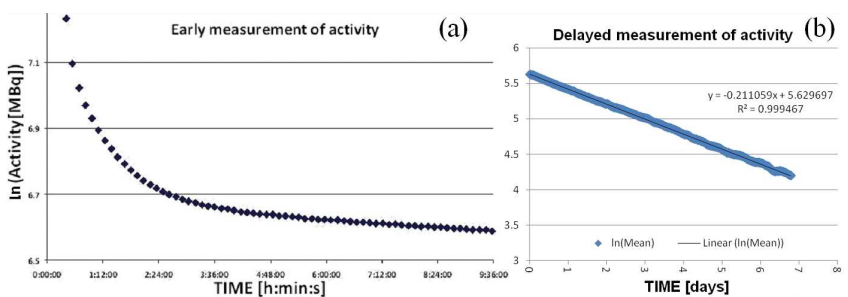

Fig. 6. Early (a) and delayed (b) measurements of activity from ${ }^{89} \mathrm{Zr}$ production with $0.5 \mathrm{~mm}$ thick niobium beam degrader showing that good base for ${ }^{89 g} \mathrm{Zr}$ activity extrapolation constitute delayed measurements after $4 \mathrm{~h}$ from EOB.

TABLE I

Zirconium 89 and its impurities' half lives expected spectral characteristics.

\begin{tabular}{c|c|c}
\hline \hline \multicolumn{3}{c}{ Expected energy spectrum for: } \\
\hline${ }^{89} \mathrm{Zr}$ & ${ }^{88} \mathrm{Zr}$ & ${ }^{88} \mathrm{Y}$ \\
$78.41 \mathrm{~h}$ & $83.4 \mathrm{~d}$ & $106.6 \mathrm{~d}$ \\
\hline $511 \mathrm{keV} 23 \%$ & $393 \mathrm{keV} 97 \%$ & $511 \mathrm{keV} 20 \%$ \\
$909 \mathrm{keV} 99 \%$ & & $1836 \mathrm{keV} 99 \%$ \\
$1713 \mathrm{keV} 0.8 \%$ & & $898 \mathrm{keV} 94 \%$ \\
$1745 \mathrm{keV} 0.1 \%$ & & $2734 \mathrm{keV} 0.7 \%$ \\
$1657 \mathrm{keV} 0.1 \%$ & & $851 \mathrm{keV} 0.1 \%$
\end{tabular}

Production of ${ }^{89} \mathrm{Zr}$ with $500 \mu \mathrm{m}$ thick niobium beam degrader $\left(E_{\mathrm{p}}=9.8 \mathrm{MeV}\right)$ was achieved, without producing either ${ }^{88} \mathrm{Zr}$ or ${ }^{88} \mathrm{Y}$ (Fig. 7 ) and resulted in yields of 8 to $9 \mathrm{MBq} / \mu \mathrm{Ah}$.

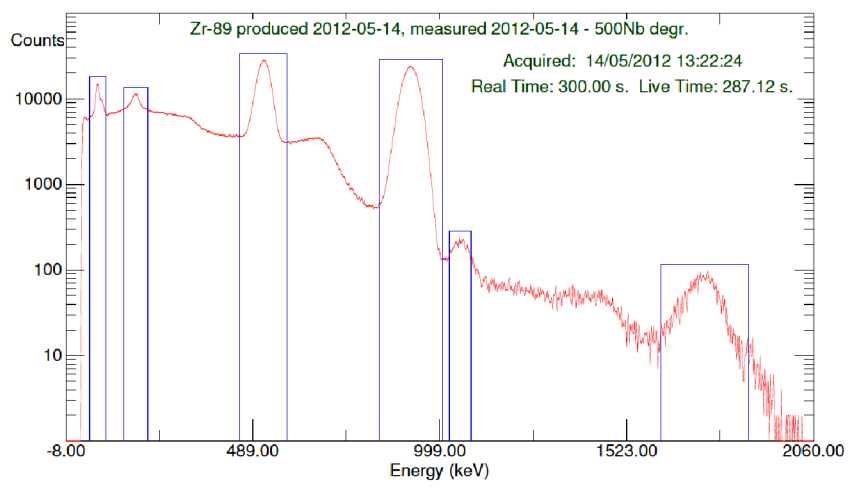

Fig. 7. Energy spectrum from ${ }^{89} \mathrm{Zr}$ production with $0.5 \mathrm{~mm}$ thick niobium beam degrader shows the characteristic 511 and $909 \mathrm{keV}$ gamma emissions from ${ }^{89} \mathrm{Zr}$.

The energy spectrum from ${ }^{89} \mathrm{Zr}$ produced using niobium foil thickness of $400 \mu \mathrm{m}$ (Fig. 8) has energy peaks at $511 \mathrm{keV}$ and $909 \mathrm{keV}$ and is consistent with ${ }^{89} \mathrm{Zr}$, too.

Production of ${ }^{89} \mathrm{Zr}$ with $400 \mu \mathrm{m}$ thick niobium foil $\left(E_{\mathrm{p}}=11.6 \mathrm{MeV}\right)$ results in a higher yield $(14-16 \mathrm{MBq} / \mu \mathrm{Ah})$ without producing evidence of ${ }^{88} \mathrm{Zr}$ or ${ }^{88} \mathrm{Y}$ impurities on spectra measured 2 months after EOB (Fig. 8). More accurate measurements with a HPGe detector show (Fig. 9) that, beside the characteristic 511,

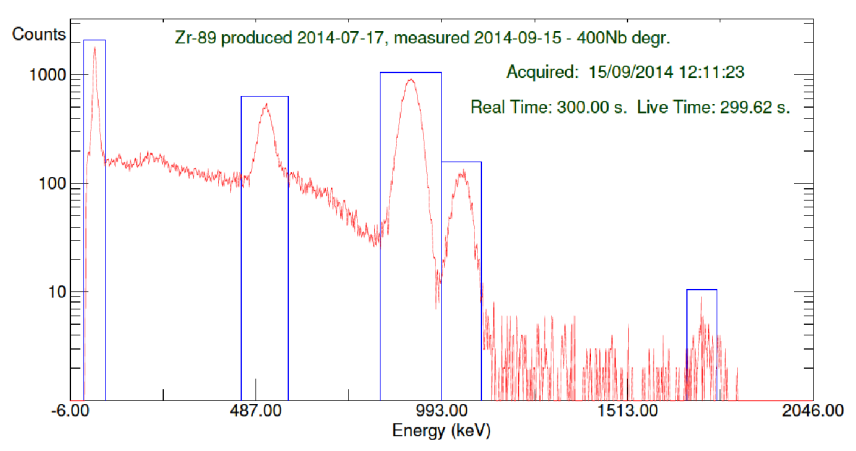

Fig. 8. Energy spectrum from ${ }^{89} \mathrm{Zr}$ production with $0.4 \mathrm{~mm}$ thick niobium beam degrader measured 2 months after EOB also shows mainly the characteristic 511 and $909 \mathrm{keV}$ gamma emissions from ${ }^{89} \mathrm{Zr}$.

$909 \mathrm{keV}$ gamma emissions and possible summation or Compton scatter peaks, only a very minor emissions from ${ }^{89} \mathrm{Zr}$ (Table I) are present around $1.7 \mathrm{MeV}$ energy value.
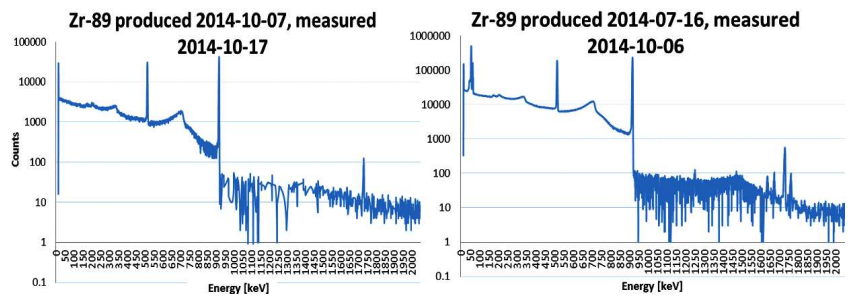

Fig. 9. Energy spectra for ${ }^{89} \mathrm{Zr}$ production with $0.4 \mathrm{~mm}$ thick Niobium beam degrader measured with HPGe detector show the characteristic 511 and $909 \mathrm{keV}$ gamma emissions from ${ }^{89} \mathrm{Zr}$ and some minor peaks around $1.7 \mathrm{MeV}$ energy value what is fully consistent with Tab. I values for ${ }^{89} \mathrm{Zr}$.

Comparison of these results is consistent with values reported in the literature [7]. However, from the summary of the production yields for ${ }^{89} \mathrm{Zr}$ presented by Taghlio et al. [9], it is obvious that our yield is not as high as published by some other authors $[3,9,10]$. There is still scope to increase our yield by varying parameters such as increasing the energy for beam protons, changing the method of target preparation or altering the target thickness or changing the beam degradation. However, we have achieved our principle aim of proving that it is possible to produce an isotopically pure ${ }^{89} \mathrm{Zr}$ with a typical low energy cyclotron configuration.

\section{Conclusions}

The production of pure ${ }^{89} \mathrm{Zr}$ with a CYCLONE $18 / 9$ and COSTIS STS is possible. It is necessary to wait at least $4 \mathrm{~h}$ before measuring the activity in order to calculate the ${ }^{89} \mathrm{Zr}$ activity at the end of cyclotron production. Degrading the proton beam to $10 \mathrm{MeV}$ produces radionuclidically pure ${ }^{89} \mathrm{Zr}$ with yields from 8 to $9 \mathrm{MBq} / \mu \mathrm{Ah}$. Whilst this is enough for pre-clinical use, the yield is 
not enough for either clinical use or commercial supply. Using thinner beam degraders to increase the proton beam energy increases the radionuclidic yield up to 15.5 $\mathrm{MBq} / \mu \mathrm{Ah}$ without the presence of radionuclidic impurities. Further improvement of the yield is planned as the value is not very high comparing to the other literature examples [9]. However reduction of impurities might be a challenge.

TABLE II

Zirconium 89 productions parameters and yields.

\begin{tabular}{c|c|c|c|c|c}
\hline \hline $\begin{array}{c}\text { Beam } \\
\text { time } \\
{[\mathrm{h}]}\end{array}$ & $\begin{array}{c}\text { Beam } \\
\text { current } \\
{[\mathrm{uA}]}\end{array}$ & $\begin{array}{c}\text { Niobium } \\
\text { thickness } \\
{[\mu \mathrm{m}]}\end{array}$ & $\begin{array}{c}\mathrm{Beam} \\
\text { energy } \\
{[\mathrm{MeV}]}\end{array}$ & $\begin{array}{c}\text { Average } \\
\text { yield of the } \\
\text { EOB }[\mathrm{MBq}]\end{array}$ & $\begin{array}{c}\text { Zr activity } \\
\text { E9 } \mathrm{Y}(\mathrm{p}, \mathrm{n})^{89} \mathrm{Zr} \\
\text { nuclear } \\
\text { reaction } \\
{[\mathrm{MBq} / \mathrm{uAh}]}\end{array}$ \\
\hline 3 & 20 & 500 & 9.8 & 529.5 & 8.83 \\
3 & 30 & 500 & 9.8 & 791.7 & 8.79 \\
2.1 & 30 & 400 & 11.6 & 973.4 & 15.45 \\
1.5 & 20 & 400 & 11.6 & 445 & 14.83 \\
3 & 30 & 400 & 11.6 & 1400 & 15.56 \\
3.5 & 30 & 400 & 11.6 & 1398 & 13.31 \\
6.28 & 25 & 400 & 11.6 & 2364 & 15.06
\end{tabular}

\section{Acknowledgments}

Many thanks to FlexLink, IBA (technical support), ELEX Commerce, Stephan Preusche (valuable information and advice) and Paul Rabaiotti.

\section{References}

[1] T.J. Wadas, E.H. Wong, G.R. Weisman, C.J. Anderson, Chem. Rev. 110, 2858 (2010).

[2] M.J. Vosjan, L.R. Perk, G.W.M. Visser, M. Budde, P. Jurek, G.E. Kiefer, G.A.M.S van Dongen, Nature Protocol 5, 739 (2010).

[3] M.S. Uddin, M. Hagiwara, M. Baba, F. Tarkanyi, F. Ditroi, Appl. Radiat. Isot. 63, 367 (2005).

[4] J. Zweit, S. Downey, H.L. Sharma, Appl. Radiat. Isot. 42, 199 (1991).

[5] M.A. Avila-Rodriguez, J. Rajander, J.O. Lill, K. Gagnon, J. Schlesinger, J.S. Wilson, S.A. McQuarrie, O. Solin, Nucl. Instrum. Methods Phys. Res. B 267, 1867 (2009).

[6] COSTIS - Operating Manual, TS04-80.00.00.01, Elex Commerce, 2007.

[7] M. Walther, P. Gebhardt, P. Grosse-Gehling, L. Würbach, I. Irmler, S. Preusche, M. Khalid, T. Opfermann, T. Kamradt, J. Steinbach, H.P. Saluz, Appl. Rad. Isotopes 69, 852 (2011).

[8] J.P. Holland, Y. Sheh, J.S. Lewis, Nucl. Med. Biol. 36, 729 (2009).

[9] M. Taghilo, T. Kakavand, S. Rajabifar, P. Sarabadani, Int. J. Phys. Sci. 7, 1321 (2012).

[11] S.A. Kandil, B. Scholten, Z.A. Saleh, A.M. Youssef, S.M. Qaim, H.H. Coenen, J. Radioanal. Nucl. Chem. 274, 45 (2007). 